\title{
Development and sensory evaluation of value added bakery products developed from germinated soybean (Glycine max) varieties
}

\author{
Harmeen Kaur* \\ Department of Food and Nutrition, Punjab Agricultural University, Ludhiana (Punjab), \\ INDIA \\ Navjot Kaur \\ Department of Food and Nutrition, Punjab Agricultural University, Ludhiana (Punjab), \\ INDIA \\ ${ }^{*}$ Corresponding author. E-mail: meen1894@gmail.com
}

\begin{abstract}
Soybean based bakery products were prepared by supplementing germinated soybean varieties namely SL 525, SL 744 and SL 958 with refined flour at different substitution levels and were organoleptically evaluated using nine-point hedonic rating scale for sensory attributes like appearance, color, texture, flavor, taste and overall acceptability by a semi-trained panel of 10 judges (panel included Professors and Assistant Professors). Incorporation of germinated soybean flour at 10, 20 and 30 percent levels showed both significant and non-significant difference $(p \leq 0.05)$ for products namely biscuits, muffins, bread, donuts and tarts for overall acceptability. Among varieties, biscuits were highly acceptable at 20 percent for SL 744 with score 8.0. Supplementation of 10 percent was highly acceptable and the scores for overall acceptability for muffins (8.42), donuts (8.0) of SL 958 and bread (8.01) of SL 525 were achieved. Tarts were highly acceptable at 20 percent supplementation in SL 525 with overall acceptability of 7.93. It may be concluded that soybean flour can be an economical alternative for refined flour in bakery products for future industrial commercialization. Further awareness regarding nutrient composition and utilization of the germinated soybean flour in the daily diet needs to be generated.
\end{abstract}

Keywords: Bakery products, Germinated soybean, Overall acceptability, Sensory evaluation.

\section{INTRODUCTION}

Bakery products in India are gaining interest with onset on days such that it can provide an ideal matrix by which functionality can be transferred to the consumer in economical and feasible way (Majid et al., 2014). The bakery goods are mostly prepared from refined wheat flour so therefore there is a need for cereals and millets to be substituted amongst each other for fulfilment of deficiencies of nutrients among the population (Dhingra and Jood, 2001)

Soybean (Glycine max) is identified as 'Miracle bean' for its high nutrient content along with its health related benefits. It is species of legume which is categorized under the family leguminosae with sub family papillionnideae native to East and South East Asia (Alabi et al., 2001). Soybean is a widely grown valuable crop in the central part of India where the bulk is utilized for producing oil or for animal feed, while considerably small usage for human or direct consumption which is increasing steadily (Singh, 2016). It is superior to all other plant foods because it has a good balance of all essential amino acids. It is economical and preeminent than the high priced meat proteins for a vegetarian diet. Considering its nutritional attributes, mainly its high protein and fat content, provided with the significant potential for cost-effective improvement of daily diets, helps in substantial reduction of protein-energy malnutrition (Goel et al., 2018). It contains good amount of essential macro nutrients for regulating good nutrition which includes complete protein (40 percent), carbohydrates (18 percent) and fat (18 percent). The moisture content is 9 percent and fibre (10 percent) with other micro nutrients (5 percent) like folic acid, calcium, potassium and iron (Singh, 2009).

Soybean when germinated, boosts the nutritive value and inactivates the anti-nutritional components. Germination of soybean is considered as the naturally occurring complex biological process where the reactions are involved that not only enhances the sensorial quality but also increases its nutritional value (Liu, 2004). It is effective and 
value-added technological approach in order to enhance the nutritional quality of soybeans in Asian countries due to its digestibility (Cho et al., 2009). Germination also inactivates its antinutritional components or the undesirable substances namely trypsin inhibitors, phytic acid, oligosaccharides and components with lipoxygenase activity that is present in it (Ramadan 2012).

Soy products are considered significant due to its good nutritional and functional qualities and due to presence of its high protein and oil content along with the presence of phytochemicals namely isoflavones which helps in reduction of cholesterol thus reducing heart diseases and regulation of menopause (Mishra and Chandra 2012). The regular consumption of soybean is linked with prevention of certain diseases namely diabetes, atherosclerosis and cancer (Mohammadi et al., 2015).

Functional food development is emerging as an interesting and important field in the food industry lately where soybean fortified bakery products received a renewed interest owing to their nutritional composition. It is therefore considered to be an essential part of functional foods as well as it can be used to enhance the product quality (Ahmad et al 2014).Use of soy flour is valued not only as a corrective of bakery product but also have a positive effect on health. Furthermore, its addition in bakery products like bread increases the amount of protein in food (Hegstad, 2008). The addition and supplementation of soybean flour with other cereal based products give the complete and overall essential amino acid balance thus, eradicating the protein calorie malnutrition in the world. The objective of the study was to conduct the organoleptic evaluation of bakery products developed by using germinated soybean varieties.

\section{MATERIALS AND METHODS}

Procurement and processing of germinated soybean varieties: Soybean (Glycine max) seeds of three varieties- SL 525, SL 744 and SL 958 were procured from Department of Plant Breeding and Genetics, College of Agriculture, Punjab Agricultural University, Ludhiana. Soybean seeds were sorted based on size, colour, and then thoroughly washed with water to remove any residues from the seed surface along with dirt or any other foreign material. After surface cleaning, the seeds were soaked in warm distilled water for 16-18 hours. The germination process was induced such that the seeds were placed (wrapped tightly) in sterilized wet cotton muslin cloth at room temperature in dark conditions, away from direct sunlight. The seeds were left to germinate for about 24 hours. The cloth was kept moist to support the germination process. After germination, the grains were boiled for 1 hour to remove trypsin inhibitor. The seeds were later dried at $60^{\circ} \mathrm{C}$ up to 10 percent moisture content using solar or mechanical dryer. The dried soybean seeds were de -vegetated and grinded to make germinated soybean flour. Soybean flour was packed and stored in sterilized packets that was further used for analysis and in product development.

Development of value added bakery products by incorporation of germinated soybean flour: Germinated soybean based products such as biscuits, muffins, bread, donuts and tarts were prepared using refined flour for control and test samples by supplementing 10, 20 and 30 percent of germinated soybean flour in the Experiential learning bakery unit of Department of Food and Nutrition, College of Home Science, Punjab Agricultural University, Ludhiana.

Biscuits: Fat $(50 \mathrm{~g})$ was rubbed on a clean surface. Refined flour $(100 \mathrm{~g})$ was sifted with baking powder $(0.5 \mathrm{~g})$ and baking soda $(0.5 \mathrm{~g})$. Refined sugar $(50 \mathrm{~g})$ was added gradually to fat. Then the sifted dry ingredients were added in fat. A smooth dough was prepared using milk $(10 \mathrm{ml})$ dissolved in ammonium bicarbonate $(0.5 \mathrm{~g})$. The dough was rolled to $1 / 4^{\text {th }}$ thickness and desired shapes were cut with cookie cutter, placed in greased baking tray and baked at $150^{\circ} \mathrm{C}$ for 20 minutes.

Muffins: Dry ingredients (refined wheat flour$100 \mathrm{~g}$, milk powder-35g, baking powder-3.5g, baking soda-3.5g) were sifted together. Fat $(50 \mathrm{~g})$ and refined sugar $(65 \mathrm{~g})$ were creamed until light and fluffy. The dry ingredients were added gently by using cut and fold method along with water from another side until desired ribbon like consistency was achieved. The mixture was poured into greased and dusted muffin tray and $3 / 4^{\text {th }}$ space was left unfilled from the top. The muffins were baked at $190^{\circ}$ for $25-30$ minutes.

Bread: Fresh yeast $(7.5 \mathrm{~g})$ was dissolved with sugar $(15 \mathrm{~g})$ in little amount of lukewarm water for preparation of flying ferment. The refined flour $(250 \mathrm{~g})$ with salt $(5 \mathrm{~g})$ was weighed and sieved. Dough was prepared by adding dissolved yeast and water required. It was kneaded to form the gluten by stretching it. Oil $(100 \mathrm{ml})$ was added and was kneaded to stop the gluten formation. Dough was kept for proofing at temperature $43-50^{\circ} \mathrm{C}$ for 15-20 minutes approximately until it was doubled in the volume. After proofing, the dough was rolled in a ball and placed in greased bread pan and left for final proofing for one hour. Bread was baked at $200^{\circ} \mathrm{C}$ for 25 minutes.

Donuts: Yeast $(6 \mathrm{~g})$ and sugar $(2 \mathrm{~g})$ were added to warm milk $(5 \mathrm{ml})$. The mixture was left for 5 minutes to activate the yeast. All the ingredients (refined flour-100g, salt-2g, milk powder-20g) were sieved and mixed. Flying ferment once ready was added to the dry ingredients and a dough was prepared out of it with milk $(55 \mathrm{ml})$. The consistency of dough was sticky, so butter $(6 \mathrm{~g})$ was added 
to knead it. The kneaded ball was kept in dusted bowl for one hour. After one hour, the dough was rolled by rolling pin and the donuts were cut by donut cutter and kept for $2^{\text {nd }}$ proofing for another hour. After they were proofed, the donuts were deep fried.

Tarts: Fat $(70 \mathrm{~g})$ and refined sugar $(35 \mathrm{~g})$ were creamed together. Refined flour $(100 \mathrm{~g})$ and salt (a pinch) was mixed with butter using fingers. A ball was made out of it and rested for $10-15$ minutes. Ball was levelled with a rolling pin and cut into shapes with donut cutter. It was placed into tart molds and pricked with a fork. Extra batter was removed from the sides with knife. Tarts were baked at $180^{\circ} \mathrm{C}$ for 20 minutes and left to cool down.

Sensory evaluation: Soybean based developed value-added bakery products were organoleptically evaluated by a panel of 10 semi trained judges who were familiar with major sensory attributes of food products from the Department of Food and Nutrition, College of Home Science, Punjab Agricultural University, Ludhiana using a 9-point hedonic rating scale. The judges were served with the baked products constituting of one control and three test samples. The control sample (C) was prepared by standardized method without any supplementation while the test samples were prepared with substitution of refined flour with germination soybean flour at the ratios of 10 percent (E1), 20 percent (E2) and 30 percent (E3). The coding of samples was changed with every sample and with new product to reduce the obviousness. The panelists were asked to score the samples for all the sensory attributes like colour, flavour, texture, appearance and its overall acceptability by using 9-point hedonic rating scale (Rangana, 2002). The degree to which a product was liked was hence expressed with scores as: liked extremely-9 points, liked very much-8 points, liked moderately-7 points, liked slightly- 6 points, neither liked nor disliked-5 points, disliked slightly4 points, disliked moderately-3 points, disliked very much- 2 points, disliked extremely-1 point.

Statistical analysis: The collected data was analyzed with the help of various statistical tools such as mean and standard deviation. To the test the significance difference between control and test samples of developed products, ANOVA and Kruskal walis t-test, was applied using SPSS 16 software.

\section{RESULTS AND DISCUSSION}

Sensory evaluation of developed products: Sensory evaluation of different germinated soybean based value added bakery products is presented in Table 1 and Table 2. Four samples of each product were prepared by using refined flour and germinated flour prepared from three soybean varieties. The samples constituted of one control sample which was prepared from refined wheat flour while the other three experimental samples were supplemented with germinated soybean flour at E1 (10\%), E2 (20\%) and E3 (30\%) level using standardized recipe.

Biscuits: The results revealed that for variety SL 525, the most acceptable level for incorporating germinated soybean flour was E1 with respect to all the sensory parameters followed by E3 and E2 with an overall acceptability score of $7.94,7.36$ and 7.18 respectively. However, the control sample was the least preferable with an overall acceptability score of 6.76 . Amongst the variety SL 744, the highest score of overall acceptability i.e. 8.00 score was given to the sample code E2 followed by $E 3$ and $E 1$ with 7.46 and 7.40 respectively with marginal difference. In variety SL 958, E3 with 30 percent soybean flour was the most acceptable amongst E2 and E1 with the overall score of 7.56, 7.28 and 7.02 respectively. The control sample was least preferred amongst the other three sample with an overall score of 6.68 based on all the attributes. Out of three varieties, SL 744 received the highest score of 8.00 followed by SL 525 with 7.94 and SL 958 with 7.56 based on overall acceptability score. Awasthi et al (2012) conducted organoleptic evaluation of soy fortified high protein and high calorie biscuits that showed that in regard to flavour and taste, appearance and texture, colour and overall acceptability, sensory characteristics of T3 with 10 percent soy flour were found to be the be highly accepted. According to Ayo et al (2014), when malted soybean flour is added, it simultaneously decreases the mean score of the general acceptability from 7.95 to 4.25 with the increase by 0 to 50 percent of malted flour. The accepted product contained 10 percent malted soybean.

Muffins: The results showed that for variety SL 525 the mean score of overall acceptability ranged from 7.66 to 8.00 . Significant difference was observed among the mean score of samples and it was highest in E2 followed by $\mathrm{C}, \mathrm{E} 1$ and $\mathrm{E} 3$ the values being $8.00,7.88,7.66$ and 6.85 . Similarly, for variety SL 744 , E2 had highest score of overall acceptability i.e. 8.30 while the scores of $C, E 1$ and E2 were $7.42,7.94$ and 7.88 , respectively. There was a significant difference among the samples of SL 744. For variety SL 958 , the mean score differed significantly, and the score was maximum for $E 1$ followed by $C, E 3$ and $E 2$, the values being $8.42,7.50,7.44$ and 7.30 . Comparison of overall acceptability of all the three varieties revealed that SL 958 (8.42) scored highest followed by SL 744 i.e. 8.30 and SL 525 i.e. 8.00 but no significant difference was observed between the three varieties. Shahraki et al (2013) revealed that in relation with organoleptic properties, with increment of soya flour up to the level 25 percent, softness and texture integrity is increased. Accord- 
Kaur, H. and Kaur, N. / J. Appl. \& Nat. Sci. 11(1): 211-216 (2019)

Table 1. Organoleptic scores of donuts and tarts using germinated soybean flour (Mean $\pm S D$ ).

\begin{tabular}{cccccccc}
\hline Varieties & Levels & Appearance & Color & Texture & Flavor & Taste & $\begin{array}{c}\text { Overall } \\
\text { Acceptability }\end{array}$ \\
\hline Donuts & & & & & & \\
\hline \multirow{2}{*}{ SL 525 } & C & $7.6 \pm 0.7$ & $7.8 \pm 0.79$ & $8.0 \pm 0.82$ & $7.8 \pm 0.79$ & $7.9 \pm 0.74$ & $7.82 \pm 0.63$ \\
& E1 & $7.5 \pm 0.71$ & $7.8 \pm 0.92$ & $7.8 \pm 0.63$ & $7.8 \pm 1.03$ & $7.9 \pm 0.88$ & $7.76 \pm 0.75$ \\
& E2 & $7.8 \pm 0.42$ & $7.9 \pm 0.74$ & $7.9 \pm 0.32$ & $7.8 \pm 0.63$ & $8.0 \pm 0.67$ & $7.88 \pm 0.36$ \\
& E3 & $7.0 \pm 0.82$ & $7.2 \pm 0.79$ & $6.8 \pm 1.03$ & $7.0 \pm 1.05$ & $6.8 \pm 1.03$ & $6.96 \pm 0.85$ \\
& C & $7.5 \pm 0.53$ & $7.5 \pm 0.53$ & $7.6 \pm 0.52$ & $7.6 \pm 0.52$ & $7.6 \pm 0.52$ & $7.56 \pm 0.44$ \\
SL 744 & E1 & $7.9 \pm 0.74$ & $7.9 \pm 0.74$ & $7.7 \pm 1.06$ & $7.9 \pm 0.88$ & $8.0 \pm 0.94$ & $7.88 \pm 0.82$ \\
& E2 & $7.4 \pm 0.52$ & $7.3 \pm 0.67$ & $7.5 \pm 0.85$ & $7.4 \pm 0.52$ & $7.5 \pm 0.53$ & $7.42 \pm 0.54$ \\
& E3 & $7.0 \pm 0.82$ & $7.2 \pm 0.63$ & $7.2 \pm 0.92$ & $7.4 \pm 0.84$ & $7.2 \pm 0.79$ & $7.20 \pm 0.72$ \\
& C & $8.0 \pm 0.67$ & $8.2 \pm 0.42$ & $8.0 \pm 0.67$ & $8.0 \pm 0.67$ & $8.2 \pm 0.63$ & $8.08 \pm 0.56$ \\
SL 958 & E1 & $8.1 \pm 0.57$ & $8.0 \pm 0.67$ & $8.1 \pm 0.74$ & $7.8 \pm 0.79$ & $8.0 \pm 0.82$ & $8.00 \pm 0.47$ \\
& E2 & $7.6 \pm 0.7$ & $7.8 \pm 0.63$ & $7.3 \pm 0.48$ & $7.3 \pm 0.48$ & $7.4 \pm 0.52$ & $7.48 \pm 0.32$ \\
& E3 & $7.3 \pm 0.95$ & $7.2 \pm 1.03$ & $7.0 \pm 0.82$ & $7.2 \pm 0.79$ & $7.1 \pm 0.74$ & $7.16 \pm 0.74$ \\
\hline Tarts & & & & & & & \\
\multirow{2}{*}{ SL 525 } & C & $7.8 \pm 0.42$ & $7.8 \pm 0.42$ & $7.8 \pm 0.34$ & $7.6 \pm 0.7$ & $7.6 \pm 0.7$ & $7.73 \pm 0.46$ \\
& E1 & $7.4 \pm 0.97$ & $7.0 \pm 0.83$ & $7.2 \pm 0.79$ & $7.3 \pm 0.82$ & $7.4 \pm 0.84$ & $7.28 \pm 0.71$ \\
& E2 & $7.9 \pm 0.32$ & $8.0 \pm 0.1$ & $7.6 \pm 0.47$ & $8.0 \pm 0.5$ & $8.0 \pm 0.5$ & $7.93 \pm 0.24$ \\
& E3 & $6.9 \pm 0.74$ & $6.9 \pm 0.88$ & $6.4 \pm 0.9$ & $6.6 \pm 0.84$ & $6.6 \pm 0.67$ & $6.70 \pm 0.68$ \\
& C & $7.8 \pm 0.42$ & $7.8 \pm 0.42$ & $7.8 \pm 0.34$ & $7.6 \pm 0.7$ & $7.6 \pm 0.7$ & $7.73 \pm 0.46$ \\
SL 744 & E1 & $6.5 \pm 1.18$ & $6.6 \pm 1.06$ & $6.5 \pm 1.05$ & $6.6 \pm 0.82$ & $6.9 \pm 0.88$ & $6.64 \pm 0.85$ \\
& E2 & $7.4 \pm 0.69$ & $7.5 \pm 0.6$ & $7.5 \pm 0.69$ & $7.6 \pm 0.82$ & $7.8 \pm 0.63$ & $7.60 \pm 0.52$ \\
& E3 & $6.6 \pm 1.0$ & $6.6 \pm 1.0$ & $6.6 \pm 0.7$ & $6.3 \pm 0.95$ & $6.5 \pm 0.85$ & $6.54 \pm 0.67$ \\
& C & $7.8 \pm 0.42$ & $7.8 \pm 0.42$ & $7.8 \pm 0.34$ & $7.6 \pm 0.7$ & $7.6 \pm 0.7$ & $7.73 \pm 0.46$ \\
& E1 & $7.2 \pm 0.63$ & $7.4 \pm 0.69$ & $7.5 \pm 0.53$ & $7.5 \pm 0.53$ & $7.4 \pm 0.52$ & $7.41 \pm 0.43$ \\
& E2 & $6.5 \pm 0.6$ & $6.5 \pm 0.6$ & $6.3 \pm 0.67$ & $6.3 \pm 0.82$ & $6.4 \pm 0.84$ & $6.42 \pm 0.54$ \\
& E3 & $5.7 \pm 0.67$ & $5.9 \pm 0.69$ & $5.8 \pm 0.79$ & $6.0 \pm 0.94$ & $5.9 \pm 0.99$ & $5.87 \pm 0.68$ \\
\hline
\end{tabular}

*Significant at $5 \%$ level of significance $(p<0.05)$. Panel member number is 10 . Scores are based upon 9 -point hedonic scale. Levels of incorporation are presented as C - 100\% Refined wheat flour, E1 - 90\% Refined wheat flour $+10 \%$ Soybean flour, E2 - 80\% Refined wheat flour + 20\% Soybean Flour and E3 - 70\% Refined wheat flour $+30 \%$ Soybean Flour.

ing to Wang et al (2014), the overall acceptability of cakes can be influenced when the wheat flour was replaced up to 15 and 20 percent by okara (residue of soybean). Cakes with 5 percent okara substitution obtained highest sensory scores.

Bread: The scores statistically revealed that the bread developed from three varieties were nonsignificant on the basis of parameters like appearance, colour, flavour, texture, taste and overall acceptability. While considering the variety SL 525 , the most acceptable level amongst the four levels was that of control sample with an overall acceptable score of 8.32. Experimental sample E1 scored the highest acceptability of 8.01 score followed by E2 and E3 with overall scores of 6.96 and 6.53 respectively. Significant difference was observed amongst the four samples. In the variety SL 744, amongst the experimental samples highest acceptability score was reported in recorded in E1 followed by E2 and E3 with 7.76, 7.38 and 6.84 respectively. For variety SL 958, the scores recorded were such that $E 2$ received the highest overall acceptability score of 7.84 , followed by $E 1$ and $E 3$ with their respective scores of 7.63 and 6.66. However, considering all the four samples, control sample received the highest overall score of 8.32. Amongst all the three varieties, based on overall acceptance scores, SL 525 received the highest scores of 8.01 followed by SL 958 with score of 7.84 and last with SL 744 with score of 7.76 . Hence soy flour substitution at 5 percent in bread making would therefore make a good and acceptable sensory attribute with probably no significant differences from the whole wheat bread (Olaoye et al., 2006).

Donuts: The results showed that for variety SL 525 , there was significant difference in the score of overall acceptability which was highest in E2, followed by $\mathrm{C}, \mathrm{E} 1$ and E3 the values being 7.88, $7.82,7.76$ and 6.96 . Whereas for variety SL 744 the overall acceptability score was $7.56,7.88$, 7.42, and 7.20 for samples C, E1, E2 and E3, respectively. Although there was no significant difference between the samples, the acceptability was highest of sample E1 of SL 744. For variety SL 958 significant difference was observed among the samples and the score was maximum of $\mathrm{C}$ i.e. 8.08, followed by $\mathrm{E} 1$ i.e. 8.00 , E2 i.e. 7.48 and E3 i.e. 7.16. However, on comparing the overall acceptability score of all the three varieties, SL 958 scored highest (8.00) followed by 
Kaur, H. and Kaur, N. / J. Appl. \& Nat. Sci. 11(1): 211-216 (2019)

Table 2. Organoleptic scores of biscuits, muffins and bread using germinated soybean flour (Mean \pm SD).

\begin{tabular}{|c|c|c|c|c|c|c|c|}
\hline Varieties & Levels & Appearance & Color & Texture & Flavor & Taste & $\begin{array}{c}\text { Overall } \\
\text { Acceptability }\end{array}$ \\
\hline \multicolumn{8}{|l|}{ Biscuits } \\
\hline \multirow{4}{*}{ SL 525} & $\mathrm{C}$ & $6.7 \pm 1.25$ & $6.5 \pm 1.27$ & $6.9 \pm 1.1$ & $6.8 \pm 0.92$ & $6.9 \pm 0.88$ & $6.76 \pm 0.99$ \\
\hline & $\mathrm{E} 1$ & $8.0 \pm 0.67$ & $7.9 \pm 0.32$ & $7.8 \pm 0.42$ & $7.9 \pm 0.57$ & $8.1 \pm 0.57$ & $7.94 \pm 0.43$ \\
\hline & E2 & $7.2 \pm 0.79$ & $7.1 \pm 0.74$ & $7.1 \pm 0.99$ & $7.2 \pm 0.92$ & $7.3 \pm 0.95$ & $7.18 \pm 0.8$ \\
\hline & E3 & $7.4 \pm 0.84$ & $7.4 \pm 0.84$ & $7.3 \pm 0.67$ & $7.3 \pm 0.82$ & $7.4 \pm 0.7$ & $7.36 \pm 0.59$ \\
\hline \multirow{4}{*}{ SL 744} & $\mathrm{C}$ & $6.4 \pm 0.97$ & $6.6 \pm 0.97$ & $6.8 \pm 1.14$ & $6.6 \pm 0.84$ & $6.9 \pm 0.88$ & $6.66 \pm 0.88$ \\
\hline & $\mathrm{E} 1$ & $7.4 \pm 0.7$ & $7.4 \pm 0.52$ & $7.4 \pm 0.52$ & $7.3 \pm 0.48$ & $7.5 \pm 0.71$ & $7.40 \pm 0.45$ \\
\hline & E2 & $8.0 \pm 0.67$ & $8.0 \pm 0.67$ & $8.0 \pm 0.47$ & $7.9 \pm 0.57$ & $8.1 \pm 0.57$ & $8.00 \pm 0.46$ \\
\hline & E3 & $7.5 \pm 0.85$ & $7.5 \pm 0.85$ & $7.2 \pm 0.79$ & $7.5 \pm 0.85$ & $7.6 \pm 0.84$ & $7.46 \pm 0.66$ \\
\hline \multirow{4}{*}{ SL 958} & $\mathrm{C}$ & $6.7 \pm 0.67$ & $6.5 \pm 0.71$ & $6.6 \pm 0.7$ & $6.7 \pm 0.48$ & $6.9 \pm 0.57$ & $6.68 \pm 0.56$ \\
\hline & $\mathrm{E} 1$ & $6.9 \pm 0.99$ & $7.1 \pm 0.88$ & $7.1 \pm 0.99$ & $7.0 \pm 1.05$ & $7.0 \pm 1.05$ & $7.02 \pm 0.95$ \\
\hline & E2 & $7.4 \pm 0.84$ & $7.2 \pm 0.79$ & $7.2 \pm 0.92$ & $7.3 \pm 0.95$ & $7.3 \pm 0.95$ & $7.28 \pm 0.77$ \\
\hline & E3 & $7.5 \pm 0.53$ & $7.6 \pm 0.52$ & $7.5 \pm 0.53$ & $7.5 \pm 0.53$ & $7.7 \pm 0.48$ & $7.56 \pm 0.37$ \\
\hline \multicolumn{8}{|l|}{ Muffins } \\
\hline \multirow{4}{*}{ SL 525} & $C$ & $8.0 \pm 0.47$ & $7.7 \pm 0.82$ & $7.9 \pm 0.57$ & $7.9 \pm 0.57$ & $7.9 \pm 0.57$ & $7.88 \pm 0.56$ \\
\hline & E1 & $7.7 \pm 0.48$ & $7.5 \pm 0.53$ & $7.5 \pm 0.53$ & $7.8 \pm 0.42$ & $7.8 \pm 0.42$ & $7.66 \pm 0.34$ \\
\hline & E2 & $7.9 \pm 0.57$ & $7.9 \pm 0.74$ & $8.0 \pm 0.47$ & $8.0 \pm 0.47$ & $8.2 \pm 0.63$ & $8.00 \pm 0.5$ \\
\hline & E3 & $6.45 \pm 0.83$ & $6.65 \pm 0.82$ & $6.9 \pm 0.99$ & $7.05 \pm 0.83$ & $7.2 \pm 0.92$ & $6.85 \pm 0.75$ \\
\hline \multirow{4}{*}{ SL 744} & $\mathrm{C}$ & $7.5 \pm 0.53$ & $7.5 \pm 0.53$ & $7.2 \pm 0.63$ & $7.5 \pm 0.71$ & $7.4 \pm 0.52$ & $7.42 \pm 0.44$ \\
\hline & E1 & $8.0 \pm 0.67$ & $8.1 \pm 0.74$ & $7.7 \pm 0.67$ & $7.8 \pm 0.63$ & $8.1 \pm 0.74$ & $7.94 \pm 0.55$ \\
\hline & E2 & $8.2 \pm 0.63$ & $8.4 \pm 0.7$ & $8.2 \pm 0.63$ & $8.3 \pm 0.67$ & $8.4 \pm 0.7$ & $8.30 \pm 0.56$ \\
\hline & E3 & $7.85 \pm 0.75$ & $7.75 \pm 0.63$ & $7.8 \pm 0.63$ & $8.0 \pm 0.82$ & $8.0 \pm 0.82$ & $7.88 \pm 0.66$ \\
\hline \multirow{4}{*}{ SL 958} & $C$ & $7.3 \pm 0.48$ & $7.4 \pm 0.52$ & $7.4 \pm 0.84$ & $7.6 \pm 0.7$ & $7.8 \pm 0.63$ & $7.50 \pm 0.45$ \\
\hline & $\mathrm{E} 1$ & $8.3 \pm 0.67$ & $8.4 \pm 0.52$ & $8.3 \pm 0.67$ & $8.5 \pm 0.53$ & $8.6 \pm 0.52$ & $8.42 \pm 0.5$ \\
\hline & E2 & $7.2 \pm 1.03$ & $7.0 \pm 0.94$ & $7.3 \pm 1.25$ & $7.4 \pm 1.17$ & $7.6 \pm 0.97$ & $7.30 \pm 1.03$ \\
\hline & E3 & $7.1 \pm 0.88$ & $7.4 \pm 0.52$ & $7.6 \pm 0.7$ & $7.6 \pm 0.7$ & $7.5 \pm 0.85$ & $7.44 \pm 0.62$ \\
\hline \multicolumn{8}{|l|}{ Bread } \\
\hline \multirow{5}{*}{ SL 525} & $C$ & $8.4 \pm 0.52$ & $8.4 \pm 0.52$ & $8.4 \pm 0.52$ & $8.2 \pm 0.79$ & $8.2 \pm 0.79$ & $8.32 \pm 0.61$ \\
\hline & $\mathrm{E} 1$ & $7.8 \pm 0.42$ & $8.0 \pm 0.47$ & $7.95 \pm 0.16$ & $8.1 \pm 0.32$ & $8.2 \pm 0.42$ & $8.01 \pm 0.2$ \\
\hline & E2 & $7.15 \pm 0.88$ & $7.25 \pm 0.63$ & $6.3 \pm 0.95$ & $7 \pm 0.67$ & $7.1 \pm 0.57$ & $6.96 \pm 0.62$ \\
\hline & E3 & $6.6 \pm 1.07$ & $6.85 \pm 0.67$ & $5.9 \pm 0.74$ & $6.6 \pm 0.84$ & $6.7 \pm 0.82$ & $6.53 \pm 0.71$ \\
\hline & $\mathrm{C}$ & $8.4 \pm 0.52$ & $8.4 \pm 0.52$ & $8.4 \pm 0.52$ & $8.2 \pm 0.79$ & $8.2 \pm 0.79$ & $8.32 \pm 0.61$ \\
\hline \multirow{3}{*}{ SL 744} & E1 & $7.7 \pm 0.82$ & $7.9 \pm 0.74$ & $8.0 \pm 0.67$ & $7.6 \pm 0.7$ & $7.6 \pm 0.7$ & $7.76 \pm 0.62$ \\
\hline & E2 & $7.45 \pm 0.5$ & $7.35 \pm 0.67$ & $7.3 \pm 0.48$ & $7.4 \pm 0.52$ & $7.4 \pm 0.52$ & $7.38 \pm 0.45$ \\
\hline & E3 & $6.7 \pm 1.06$ & $6.8 \pm 1.03$ & $6.5 \pm 0.71$ & $7.1 \pm 0.88$ & $7.1 \pm 0.88$ & $6.84 \pm 0.86$ \\
\hline \multirow{4}{*}{ SL 958} & $\mathrm{C}$ & $8.4 \pm 0.52$ & $8.4 \pm 0.52$ & $8.4 \pm 0.52$ & $8.2 \pm 0.79$ & $8.2 \pm 0.79$ & $8.32 \pm 0.61$ \\
\hline & $\mathrm{E} 1$ & $7.75 \pm 0.63$ & $7.65 \pm 0.67$ & $7.55 \pm 0.83$ & $7.6 \pm 0.84$ & $7.6 \pm 0.84$ & $7.63 \pm 0.7$ \\
\hline & E2 & $7.9 \pm 0.74$ & $7.9 \pm 0.74$ & $7.5 \pm 1.08$ & $7.9 \pm 0.74$ & $8.0 \pm 0.82$ & $7.84 \pm 0.79$ \\
\hline & E3 & $6.7 \pm 0.82$ & $6.8 \pm 0.92$ & $6.2 \pm 0.63$ & $6.7 \pm 0.95$ & $6.9 \pm 1.2$ & $6.66 \pm 0.81$ \\
\hline
\end{tabular}

*Significant at $5 \%$ level of significance $(p<0.05)$. Panel member number is 10 . Scores are based upon 9-point hedonic scale. Levels of incorporation are presented as C - 100\% Refined wheat flour, E1 - 90\% Refined wheat flour $+10 \%$ Soybean flour, E2 - $80 \%$ Refined wheat flour $+20 \%$ Soybean Flour and E3 - 70\% Refined wheat flour $+30 \%$ Soybean Flour

SL 525 (7.88) and SL 744 (7.88) but no significant difference was found. Donuts containing soy protein absorb less fat during frying because the fat is prevented from penetrating into the interior. This may be due to heat denaturation of the protein on the donut surface, which produces a barrier to fat absorption. The result is a higher quality donuts that is more economical due to lower frying oil use. Used in the range of 3 to 3.5 percent of the formula, soy flour also gives doughnuts a good crust color, improved shape, higher moisture absorption with resulting improvement in shelf-life, and a texture with shortness or tenderness (Endres 2001).
Tarts: The results revealed in variety SL 525, the highest score was obtained by E2 for all sensory parameters with overall acceptability of 7.93 followed by $\mathrm{C}, \mathrm{E} 1$ and least with E3 with scores $7.73,7.28$ and 6.70 respectively. There was a significant difference observed amongst these samples in variety SL 525 . In variety SL 744 , the sample with code E2 was highly acceptable with overall score of 7.60 . The second preferred score was given for sample $C$ with score of 7.73 followed by E1 with 6.64 score and E3 was found to be 6.54 . In variety SL 744 , there was a significant difference amongst all the samples. In the third variety, SL 958 , the C sample received the high- 
est overall score of 7.73 followed by E1, E2 and E3 with the scores $7.41,6.42$ and 5.87 respectively. There was however a significant difference observed amongst the experimental samples in SL 958 variety. Amongst all the three varieties, on the basis of overall acceptance scores, SL 525 received the highest scores of 7.93 followed by SL 744 and 958 with same score of 7.73. Therefore, based on overall acceptability, all the three varieties namely SL 525, 744 and 958 differed significantly. The pie can be supplemented with pumpkin flesh, seed and seed kernel flour by replacing refined wheat flour at a level of 80:20, $70: 30$ and 80:20, respectively and stored well in cling wrap upto 7 days under refrigerated conditions however, the pie supplemented with seed flour (70:30) contained higher chemical and sensory properties (Sachin, 2018).

\section{Conclusion}

Bakery products prepared from germinated soybean flour was acceptable at all three levels-10, 20 and 30 percent. In biscuits, the highest score of 8.0 for all the sensory parameters was obtained by SL 744 at 20 percent. For muffins, 10 percent level of substitution of germinated soybean flour was highest in SL 958 with 8.42 score. The control sample prepared for bread obtained the highest overall acceptability with 8.32 score whereas variety SL 525 received highest score of 8.01 at 10 percent level of incorporation of germinated soybean. Donuts prepared from control sample revealed 8.08 score, while 8.0 score with 10 percent substitution in SL 958 was highest amongst the other two varieties. Tarts prepared from SL 525 had highest organoleptic score of 7.93 at 20 percent incorporation of germinated soybean. On the basis of the results, it may be concluded that products from germinated soybean flour can be prepared with high sensory and nutritional value and can be incorporated in bakery products for future industrial commercialization.

\section{REFERENCES}

1. Ahmad A, Hayat I, Arif S, Masud T, Khalid N and Ahmed A (2014) Mechanisms involved in the therapeutic effects of soybean (Glycine Max). Int J Fd Prop 17:1332-54.

2. Alabi M O, Anuonye J C, Ndaeji C F and Idowu A A (2001) Comparison of the growth and development of selected children in soybean and non-soybean producing and utilization of villages in Niger State, Nigeria. Poly Math J 2:8-12.

3. Awasthi I, Siraj P, Tripathi D M and Tripathi V (2012) Development of soy fortified high protein and high calorie supplementary biscuits. Indian J Sci Res 3: 51-58.
4. Ayo J A, Ayo V A, Popoola C, Omosebi M and Joseph $L$ (2014) Production and evaluation of malted soybean-acha composite flour bread and biscuit. Afr J Fd Sci Tech 5: 21-28.

5. Cho S Y, Lee Y N and Park H J (2009) Optimization of ethanol extraction and further purification of isoflavones from soybean sprout cotyledon. Fd Chem 117:312-17.

6. Dhingra S and Jood S (2001) Organoleptic and nutritional evaluation of wheat breads supplemented with soybean and barley flour. Fd Chem 77: 479-488.

7. Endres J (2001) Soy flour products in baking. Dissertation in Phd Rechnical foods Consultant.

8. Goel R, Kaur A and Singh J (2018) Varietal evaluation of soybean for tofu making. Asian $J$ Dairy $F d$ Res 37: 81-84.

9. Hegstad H G (2008) Nutritional and health benefits of soybean. Soy protein quality evaluation report, food and agriculture organization of the United Nations, Food and Nutrition Pp.71, Rome, Italy.

10.Liu K (ed) (2004) Soybeans as functional Foods and ingredients. AOCS Publishing, USA.

11.Majid I, Kumar V and Nayik G A (2014) Bakery industry in India - Innovations, trends and challenges. Food and Beverage News. 7:19,22,30.

12.Mishra N and Chandra R (2012) Development of functional biscuit from soy flour and rice bran. Int $J$ Agric Fd Sci 2:14-20.

13. Mohammadi S M, Mazloomi S M, Tanideh N and Rezaiaahman Z A (2015) The effects of probiotic soymilk fortified with omega-3 on blood glucose, lipid profile, haematological and oxidative stress, and inflammatory parameters in streptozotocin nictotinamide-induced diabetic rats. J Diab Res., 7: 1-9.

14. Olaoye O A Onilude A A and Idowu O A (2006) Quality characteristics of bread produced from composite flours of wheat, plantain and soybeans. Afr $J$ Biotech 5:1102-06.

15.Ramadan E A (2012) Effect of processing and cooking methods on the chemical composition, sugars and phytic acid of soybeans. Fd Public Health. 2:1115

16.Rangana S (2002) Manual of analysis of fruits and vegetable products. Tata Mcgraw-Hill Publishing Company Limited, New Delhi.

17.Sachin M (2018) Evaluation of ripe pumpkin flours and its utilization in bakery products. M.Sc Thesis, UHF, NAUNI

18.Shahraki R, Firouzi M, Harati $H$, Hesari J and Najafi M A (2013) Fortification of cake with soy flour as a functional food. J Basic Appl Sci Res 3:336-41.

19.Singh A K, Kadam D M, Sexena M and Singh R P (2009) Efficacy of defatted soy flour supplement in gulabjamun. Afr J Biochem Res 3: 130-13.

20.Singh J (2016) Effect of storage on germination and viability of soybean (Glycine max) and Niger (Guizotia abyssinica) seeds. Int J Curr Microbio App Sci 5:484-91.

21.Wang L, Wang $\mathrm{C}$, Chang $\mathrm{T}$, Shi L, Yong $\mathrm{H}$ and Cui $M$ (2014) Effect of Okara on the sensory quality of cake. $R$ Health Nutr. 2:1-4. 